\title{
BMJ Open Parental perceptions of school-based influenza immunisation in Ontario, Canada: a qualitative study
}

\author{
Donna MacDougall, ${ }^{1}$ Lois Crowe, ${ }^{2}$ Jennifer A Pereira, ${ }^{3}$ Jeffrey C Kwong, ${ }^{4}$ \\ Susan Quach, ${ }^{3}$ Anne E Wormsbecker, ${ }^{3}$ Hilary Ramsay, ${ }^{2}$ Marina I Salvadori, ${ }^{5}$ \\ Margaret L Russell, ${ }^{6}$ for the Public Health Agency of Canada/Canadian Institutes of \\ Health Research Influenza Research Network (PCIRN) Program Delivery and \\ Evaluation Group
}

To cite: MacDougall $D$, Crowe L, Pereira JA, et al. Parental perceptions of school-based influenza immunisation in Ontario, Canada: a qualitative study. BMJ Open 2014;4:e005189. doi:10.1136/bmjopen-2014005189

- Prepublication history for this paper is available online. To view these files please visit the journal online (http://dx.doi.org/10.1136/ bmjopen-2014-005189).

Received 4 March 2014 Revised 15 May 2014 Accepted 22 May 2014

\section{CrossMark}

${ }^{1}$ St Francis Xavier University, Antigonish, Nova Scotia, Canada

${ }^{2}$ Bruyère Research Institute, Ottawa, Ontario, Canada

${ }^{3}$ Public Health Ontario,

Toronto, Ontario, Canada

${ }^{4}$ Institute for Clinical

Evaluative Sciences, Toronto, Ontario, Canada

${ }^{5}$ Western University, London, Ontario, Canada

${ }^{6}$ Department of Community Health Sciences, University of Calgary, Calgary, Alberta, Canada

Correspondence to Dr Margaret Russell; mlrussel@calgary.ca

\section{ABSTRACT}

Objective: To understand the perspectives of Ontario parents regarding the advantages and disadvantages of adding influenza immunisation to the currently existing Ontario school-based immunisation programmes.

Design: Descriptive qualitative study.

Participants: Parents of school-age children in Ontario, Canada, who were recruited using a variety of electronic strategies (social media, emails and media releases), and identified as eligible (Ontario resident, parent of one or more school-age children, able to read/write English) on the basis of a screening questionnaire. We used stratified purposeful sampling to obtain maximum variation in two groups: parents who had ever immunised at least one child against influenza or who had never done so. We conducted focus groups (teleconference or internet forum) and individual interviews to collect data. Thematic analysis was used to analyse the data.

Setting: Ontario, Canada.

Results: Of the 55 participants, 16 took part in four teleconference focus groups, 35 in 6 internet forum focus groups and four in individual interviews conducted between October 2012 and February 2013. Participants who stated that a school-based influenza immunisation programme would be worthwhile for their child valued its convenience and its potential to reduce influenza transmission without interfering with the family routine. However, most thought that for a programme to be acceptable, it would need to be well designed and voluntary, with adequate parental control and transparent communication between the key stakeholder groups of public health, schools and parents.

Conclusions: These results will benefit decision-makers in the public health and education sectors as they consider the advantages and disadvantages of immunising children in schools as part of a system-wide influenza prevention approach. Further research is needed to assess the perceptions of school board and public health stakeholders.

\section{INTRODUCTION}

Children are important drivers of influenza transmission. ${ }^{1-5}$ Immunising school-age children may provide direct benefits to the children as

\section{Strengths and limitations of this study}

- Several qualitative studies from the USA have identified issues (from the perspective of parents) that are relevant to the design and implementation of programmes to deliver immunisations (including influenza immunisation) to school-age children at school.

- However, data from settings in which healthcare and influenza immunisations are universally publicly funded, and well-established programmes for delivering vaccines other than influenza vaccine at school have been lacking.

- The issues raised by parents in our study were similar to those found elsewhere, including parents in the USA.

- Our data provide guidance for programme planners to develop programmes that are acceptable to parents for delivering influenza vaccines in schools.

well as indirect benefits to high-risk groups. ${ }^{6-11}$ Canada recommends vaccination of children aged 6-59 months and individuals $\geq 65$ years, and also encourages vaccination of all healthy persons aged 5-64 years. ${ }^{12}$ The province of Ontario has provided free influenza vaccines for all residents aged 6 months or older since 2000 . However, coverage during the 2006-2007 influenza season was only $31 \%$ among children aged 12-19 years, $28 \%$ among healthy children aged 2-11 years and 37\% among children aged 211 years with chronic health conditions. ${ }^{13} 14$ Barriers to access are often cited as reasons for under-immunisation. ${ }^{15}$

In Canada all provinces and territories vaccinate children at school, although there is variance in the vaccines administered using this strategy. ${ }^{16}$ Ontario (population 13.4 million in 2012) is the only Canadian province to date where school-based influenza 
immunisation (SBII) is known to have been implemented, and it has been associated with an approximately $10 \%$ greater vaccine coverage in school-age children (39\% vs $30 \%$ for children aged $12-19$ years, $36 \%$ vs $24 \%$ for children aged 4-11 years), and a corresponding 19$24 \%$ reduction in influenza-associated physician office visits. ${ }^{14}$ SBII is a strategy to increase influenza vaccine coverage in children particularly 'where background rates are likely to be very low and improvements in coverage are needed'. ${ }^{17}$ SBII may also have the potential to reduce disparities in uptake that might exist, based on the recent Alberta experience with school delivery of adolescent-targeted human papillomavirus (HPV) vaccine delivery. ${ }^{18}$ However, the decision to implement SBII is at the discretion of each of Ontario's 36 public health units (PHUs), and the number of PHUs offering SBII was only 4 in $2010 .^{14}$

Key stakeholders for the development and implementation of any school-based immunisation programme include parents and guardians, the education sector (eg, school administrators) and the health sector (eg, public health). We conducted a qualitative study to examine and understand parents' perceptions of the advantages and disadvantages of SBII, as well as the programmatic characteristics that would contribute to the development of robust SBII programmes that are acceptable to parents in Ontario, Canada.

\section{METHODS}

We conducted a descriptive qualitative study using focus groups (FG) as our primary means of data collection, ${ }^{19}$ using key informant interviews to confirm findings with rural participants. Given Ontario's large geographical area, we chose teleconferences (maximum duration of $1 \mathrm{~h}$ ) and internet forums (asynchronous participation, approximately $15 \mathrm{~min} /$ day for 5 days) to facilitate participation by parents from across the province. Teleconferences and internet forums have been found to be as successful as face-to-face sessions for FGs. ${ }^{20} 21$

\section{Recruitment}

Between October 2012 and February 2013, we used purposeful sampling to recruit parents of school-age children living in Ontario using social media, deal forum websites, online classified ads, conventional mass media and email lists. ${ }^{22}$ Participants were eligible if they: (1) lived in Ontario; (2) had at least one child enrolled in school (kindergarten to grade 12); (3) were mostly or jointly responsible for making health decisions for their child; and (4) spoke and wrote in English. If eligible, participants were then asked questions about their demographic characteristics and to indicate their preference for a teleconference or an internet forum FG. For each FG, we invited at least twice the number of individuals to participate as needed in anticipation that many of those invited would not participate, and we offered them two or three time slots as options. We conducted the teleconference FGs at the time when the maximum number of persons were available. Individuals who preferred internet forums were provided with forum start and end dates, and asked to create an online account prior to the beginning of the first forum. We conducted recruitment in three rounds. Round 1 occurred in November 2012, Round 2 in December 2012 and Round 3 in February 2013. In Round 1, we offered a \$5 Amazon.ca electronic gift certificate to eligible participants completing both parts of the web-based eligibility questionnaire. No incentive was offered in the subsequent two rounds of recruitment. After closing recruitment in each round, we stratified participants into two heterogeneous groups to ensure within group homogeneity: (1) Ever group: parents who had ever immunised at least one child against influenza; and (2) Never group: parents who had never immunised any of their children against influenza. To ensure maximum variation in each group on other attributes, we invited individuals based on additional criteria: single parent status, geographic location (urban vs rural), gender, ethnicity and age. The last round targeted parents from rural areas. We defined rural residents as being those who had a zero in the second position of their six-digit postal code, indicating residence in an area that is not accessible by letter carriers. ${ }^{23}$

\section{Study process}

A trained facilitator (LC) moderated all FGs, with other team members (DM, JAP, SQ, HR) attending selected sessions. Researchers LC, DM, JAP and SQ had experience and/or training in qualitative methods. All members of the research team except JCK were women and all had public health experience as well as a vested interest in promoting immunisation within the public domain. None of the researchers had relationships with any of the participants prior to the study. All participants were provided with a semistructured interview guide in advance. This pilot-tested guide included a brief description of the study purpose, participant instructions and the 11 core questions. During the FGs, the participants were encouraged to share their opinions, and to build on each other's thoughts and ideas about SBII. Repeat interviews were not conducted. One individual withdrew from an FG after being deemed ineligible to participate based on disclosures made at the start of the FG. Following the FGs, we completed a round of individual interviews with rural parents as participation was low among this group. Teleconference FGs and telephone interviews were digitally recorded and transcribed verbatim by a qualified transcriptionist. Transcripts were not returned to the participants for comment. Field notes were written following each FG and interview including information about the process and personal observations. Internet forum and teleconference data were imported into NVivo 10 for analysis.

\section{Analysis}

Following each round of data collection, four research team members (LC, JAP, DM, SQ) individually coded 
the data using the process of thematic analysis. ${ }^{19} 2425$ Each person read all transcripts to generate an initial set of codes. The initial codes were then collated into potential themes, where all data were gathered relevant to each theme. The themes were then reviewed to ensure that they reflected the coded extracts as well as the entire data set. Through ongoing analysis, the themes were refined and linkages between them were identified. Team members met regularly to review the emergent themes and reach consensus. As new themes were still arising at the end of the first round of FGs, recruitment was reopened and a second round of FGs continued until saturation was reached. Following analysis, the themes were compared with the existing literature to determine congruency of the findings.

\section{Ethics and role of the funding source}

Participants gave informed consent prior to taking part in the study; the consenting process included information about the researchers and the purpose and rationale of the study. The study was funded by the Canadian Institutes of Health Research, grant number PIR 124309. The funding source had no role in the design and conduct of the study; collection, management, analysis and interpretation of the data; and preparation, review or approval of the manuscript.

\section{RESULTS}

Between November 2012 and February 2013, we conducted $10 \mathrm{FGs}$ and four key informant interviews over three rounds. Fifty-five people participated. Round 1 comprised one teleconference (6 parents) and two internet forums (15 parents) FGs. Round 2 entailed three teleconference (10 parents) and four internet forums (20 parents) FGs. Round 3 involved four key informant interviews (four parents, all rural). Of the 55 participants, $41(75 \%)$ were women, $26(47 \%)$ were 40 years or older, $34(67 \%)$ had a university degree, 25 (45\%) had more than one child, $50(91 \%)$ were from urban areas, $10(18 \%)$ identified themselves as single parents and $30(55 \%)$ had ever had a child immunised against influenza (table 1).

\section{Themes}

Two major themes describing Ontario parents' perceptions of the advantages and disadvantages of influenza

\begin{tabular}{|c|c|c|c|c|}
\hline Characteristics & $\begin{array}{l}\text { Round 1 } \\
\mathrm{n}=21(\%)\end{array}$ & $\begin{array}{l}\text { Round } 2 \\
\mathrm{n}=30(\%)\end{array}$ & $\begin{array}{l}\text { Round } 3 \\
n=4(\%)\end{array}$ & $\begin{array}{l}\text { Total } \\
\mathrm{N}=55(\%)\end{array}$ \\
\hline \multicolumn{5}{|l|}{ Influenza vaccination status } \\
\hline Ever had a child vaccinated against influenza & $12(57)$ & $14(47)$ & $4(100)$ & $30(55)$ \\
\hline Never had a child vaccinated against influenza & $9(43)$ & $16(53)$ & $0(0)$ & $25(45)$ \\
\hline \multicolumn{5}{|l|}{ Urban vs rural residence } \\
\hline Urban & $20(95)$ & $30(100)$ & $0(0)$ & $50(91)$ \\
\hline Rural & $1(5)$ & $0(0)$ & $4(100)$ & $5(9)$ \\
\hline \multicolumn{5}{|l|}{ Single (lone) parent status } \\
\hline Single parent & $3(14)$ & $7(23)$ & $0(0)$ & $10(18)$ \\
\hline Other & $17(81)$ & $23(77)$ & $4(100)$ & $44(80)$ \\
\hline Prefer not to answer & $1(5)$ & $0(0)$ & $0(0)$ & $1(2)$ \\
\hline \multicolumn{5}{|l|}{ Sex } \\
\hline Female & $11(52)$ & $26(87)$ & $4(100)$ & $41(75)$ \\
\hline Male & $10(48)$ & $4(13)$ & $0(0)$ & $14(25)$ \\
\hline \multicolumn{5}{|l|}{ Number of children } \\
\hline 1 & $13(62)$ & $15(50)$ & $2(50)$ & $30(55)$ \\
\hline 2 & $6(29)$ & $9(30)$ & $1(25)$ & $16(29)$ \\
\hline 3 or more & $2(9)$ & $6(20)$ & $1(25)$ & $9(16)$ \\
\hline \multicolumn{5}{|c|}{ Number and proportion of parents with at least one child in level of school } \\
\hline Kindergarten & $8(38)$ & $13(43)$ & $0(0)$ & $21(38)$ \\
\hline Elementary school (grades 1-6) & $7(33)$ & $18(60)$ & $3(75)$ & $28(51)$ \\
\hline Middle school (grades 7-8) & $3(14)$ & $5(17)$ & $1(25)$ & $9(16)$ \\
\hline High school (grades 9-12) & $6(29)$ & $4(13)$ & $0(0)$ & $10(18)$ \\
\hline \multicolumn{5}{|l|}{ Age range (years) } \\
\hline $20-29$ & $4(19)$ & $4(13)$ & $0(0)$ & $8(16)$ \\
\hline 30-39 & $10(48)$ & $10(33)$ & $1(25)$ & $21(38)$ \\
\hline 40 or older & $7(33)$ & $16(53)$ & $3(75)$ & $26(47)$ \\
\hline \multicolumn{5}{|l|}{ Education } \\
\hline High school & $2(10)$ & $2(7)$ & $0(0)$ & $4(8)$ \\
\hline Some postsecondary or college diploma & $3(14)$ & $10(33)$ & $3(75)$ & $16(29)$ \\
\hline University degree & $16(76)$ & $18(60)$ & $0(0)$ & $34(67)$ \\
\hline Other/no answer & $0(0)$ & $0(0)$ & $1(25)$ & $1(2)$ \\
\hline
\end{tabular}


immunisation in schools were identified: the effects of SBII at each stakeholder level and recommendations for an ideal programme (table 2). These themes mapped to the coding tree created during analysis as they had been derived directly from the data.

\section{Theme 1: Perceived effects at the individual and system level Impact on children and their families}

Pressure to immunise. Parents expressed support and concern for the fact that implementing SBII would increase pressure to have children immunised, and would force parents to make a decision. Those supportive of SBII thought that this added pressure could be beneficial, resulting in increased vaccine uptake in children.

... there are people who don't immunize their children for a variety of things, but influenza in particular...so I think that having it [influenza immunization] in school would put some pressure on some of those people to immunize their children...that could be seen as an advantage because I think that it would increase uptake... (P27)

However, others thought that the decision to vaccinate one's child against influenza should be personal, and the implementation of SBII may lead to inappropriate external influence on the decision-making process. This was especially true for those who expressed overall negative views about vaccination, or were uncertain about the merits of seasonal influenza vaccine.

I think the one disadvantage that I could think of is because it's part of the school-based program, I think some parents who may not want to use it, may feel pressured, because it is offered at school, and they may feel pressured to use it. (P23)

Integration into family life/accessible. Most parents agreed that SBII would be time saving and more convenient for families and less disruptive to the family routine than seeking immunisation at conventional healthcare locations. This issue was mentioned repeatedly by parents from rural areas, for whom influenza immunisation often required considerable travel and time due to limited access to immunisation providers and a lack of public transit.

If we miss that (clinic) then we must travel to one of the clinics in Ottawa (a 90-110 minute round trip plus time waiting in clinic) or make arrangements with our doctor. (However) in the past our GP has only been able to vaccinate the family once the clinics have finished, which is usually well past the optimal period for preventing infection. $(\mathrm{P} 46)$

...If you don't have a primary care physician...you can't get it (flu shot) done at a walk-in clinic. (P54)

Table 2 Themes arising from the data

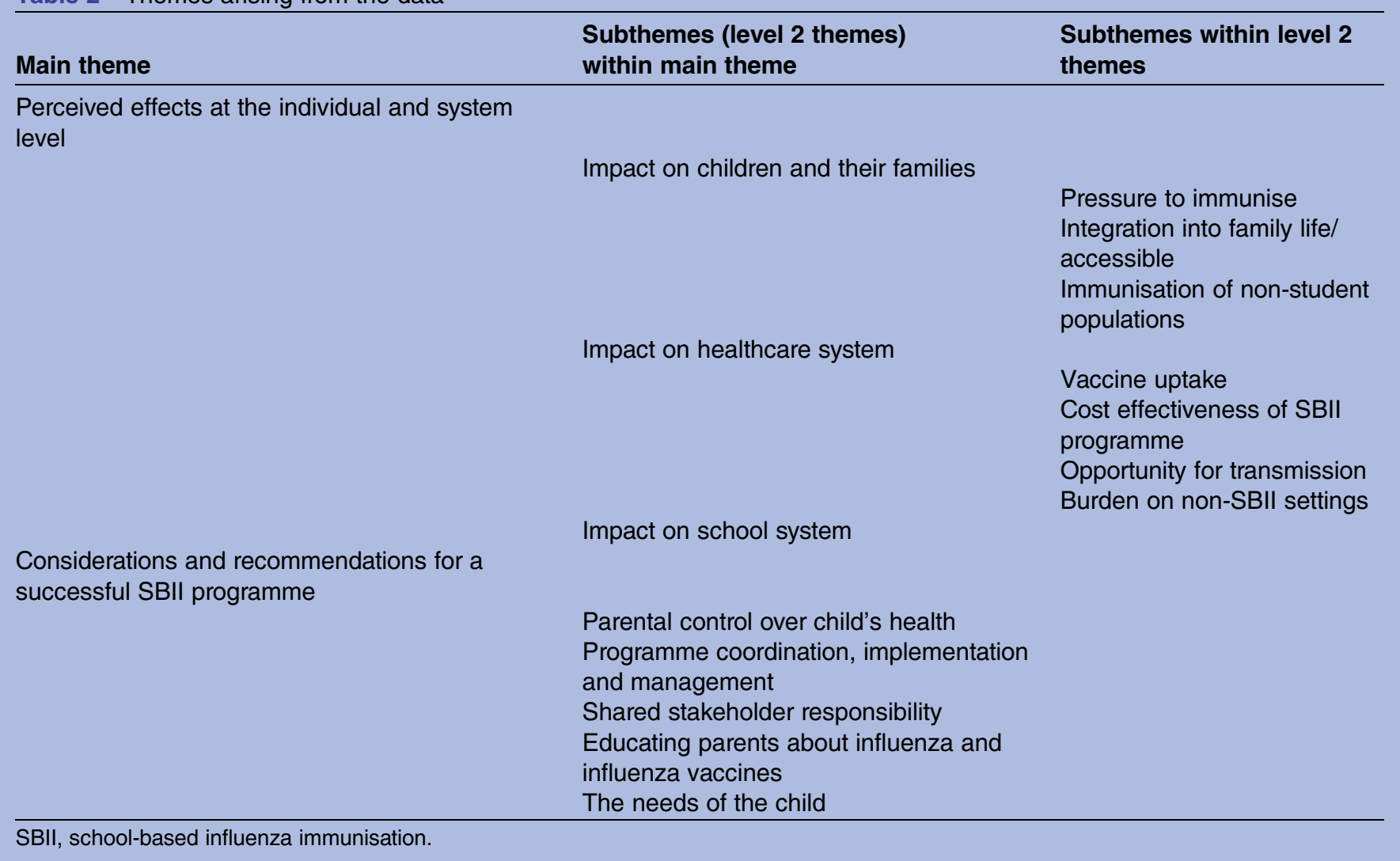


Immunisation of non-student populations: A few parents expressed concern that SBII may affect adult immunisation coverage. Since the practice of influenza immunisation was commonly carried out as a family and often for the benefit of the children, they thought that parents may be less inclined to get immunised themselves if their children were immunised at school.

\section{Impact on healthcare system}

Vaccine uptake: Many parents thought that if SBII was well developed, timed appropriately during the school year and safely implemented, it had the potential to increase influenza immunisation coverage. These parents anticipated a positive impact on the healthcare system, with increased vaccine uptake leading to decreased disease spread and healthcare utilisation.

Cost effectiveness of SBII programme: Some parents commented on the need to understand the costs of SBII before assessing its value. Several thought that if the programme increased immunisation coverage, the community-wide benefit of fewer cases of influenza would justify the increased programme costs.

I think the long term health care costs in reducing the risk of a flu epidemic, would be less than the short term costs of providing the vaccination free of charge. (P44)

However, others were unsure about who would be expected to fund the programme. These participants were concerned about additional financial costs to schools and the healthcare system, and thought that they needed more information before supporting SBII.

Perhaps the teachers would have to do more work?... Where does the budget for this come from? Would it affect school budgets at all? ( $\mathrm{p} 46$ )

Opportunity for transmission: A few parents mentioned that SBII allowed their children to get vaccinated in a setting where individuals would tend to be relatively healthy, in contrast to the perceived risk of exposure to ill persons while waiting in physician offices or in line-ups for public health mass vaccination clinics. School clinics were thus viewed as being comparatively healthy environments, decreasing opportunities for transmission of influenza to children and their families.

Burden on non-SBII settings: A small number of parents thought that introducing SBII could ease strain on the healthcare system. These parents associated currently structured influenza immunisation programmes with long line-ups in mass vaccination clinics, and thought SBII could potentially decrease the burden influenza immunisation places on family doctors and public health clinics.

\section{Impact on school system}

Parents had conflicting views on the appropriateness of using schools to deliver a healthcare programme like SBII. Some thought that schools were a suitable and convenient location to vaccinate children. Others were uncertain about the roles and responsibilities of schools compared with those of local public health. If schools were actively involved in SBII implementation, there was concern as to whether they were well equipped to coordinate the programme successfully, whether this might interfere with education and whether school-based immunisations would be recorded properly, with the mechanisms in place to track and transfer the data as needed.

My biggest concern...is the logistics of it...Who is monitoring and how are we going to do that in terms of the schedules? And beyond the schedule, how that information is going to be passed on? (P2)

There was also some apprehension as to whether SBII programme implementation was an achievable goal given the amount of coordination that would be required from the various stakeholders. A few parents were concerned whether every aspect of the programme would be considered, beyond the logistics, to reflect the best interests of children.

...I'm worried about public health lining up hundreds of kids to be immunized and only having time for the logistics of getting that done and not having the time to care for emotional states. (P51)

\section{Theme 2: Considerations and recommendations}

\section{for a successful SBII programme}

Although there were parents who were firmly against seasonal influenza vaccines for their children, many expressed that there could be value to an SBII programme, but identified several issues that would need to be addressed before they would feel comfortable using the programme.

Parental control over child's health: All parents agreed that the programme should be $100 \%$ voluntary but acknowledged that opinions were mixed on this. However, they said as long as there was a choice, they would not oppose it.

As long as these programs are optional, I think they provide a good service. Parents decide what is best for their children and there should be no pressure to participate. (P48)

Many parents thought the use of rewards for children being immunised (eg, stickers, candies) would be positive and would help increase the comfort level of the child being immunised. However, in one FG, a couple of parents expressed concerns that giving rewards only to immunised children would potentially stigmatise those who did not receive the vaccine.

Programme coordination, implementation and management: Several parents stressed that the timing of the programme was important. Planning the annual clinics at the same time of the year, in the right period for disease 
prevention and adding clinic dates to school calendars at the beginning of the year would be essential.

In the absence of experience with SBII, and in many cases, any school-based immunisation programme, some parents were unaware that nurses from the local public health agency deliver immunisation programmes (eg, for HPV and meningococcal vaccines) in schools. These parents expressed concerns about who would be giving the vaccine: Would they be professionals? Would the location and process be hygienic? Others raised concerns about how side effects or allergic reactions would be managed.

As long as it was being done in a safe clean environment and administered by trained professionals, then nothing would stop me from having my children given a flu shot at school. (P51)

...my biggest fear has always been the reaction to the vaccine, whether or not they would get the right amount of attention if there was a negative reaction. (P11)

Shared stakeholder responsibility: The majority of parents spoke of the need for effective communication between all stakeholders (school/parents/public health), to ensure everyone is well informed with appropriate information to make decisions. Keeping lines of communication open, and being sensitive to the needs of the different parent groups (such as unique cultural or economic groups or those with differing opinions about influenza immunisation) was considered essential. Parents also provided suggestions about effective communication channels.

...having an information session for new parents every year...would be wonderful. (P26)

Educating parents about influenza and influenza vaccines: Participants thought that the ideal SBII programme would include education for parents about influenza illness and influenza vaccine. Some parents perceived that influenza was not a serious disease. Others thought they needed more information about vaccine effectiveness and vaccine safety, particularly for children. Parents stressed the need for consistent messaging from sources perceived to be trustworthy. They strongly recommended that official communications be standardised to increase acceptance and decrease confusion.

The needs of the child: Some parents recommended that the programmes be flexible and provide for the differing needs of children, such as creating different approaches depending on the age of the child, or for children with special needs.

The first factor would be age. If he was young and uncomfortable with the idea then I'd pass just so I could be there with him. If he was old enough (5th grade and higher)...I'd have him immunized at school. (P47)
Parents expressed the need to provide a safe environment for the children, and to make sure that those responsible for the programme respect a child's dignity throughout the immunisation process. This would include protecting their feelings and any potential insecurities (eg, not being forced to partially disrobe in front of classmates; ensuring privacy for children afraid of needles). A couple of parents emphasised the importance of maintaining focus on the child, by describing their own past immunisation experiences that did not do this, which they felt influenced their willingness to use an SBII programme.

I think a lot of times we don't give our kids enough dignity...When I was a kid we had these scoliosis tests done and I was a chubby kid. And, you know, we'd have to remove our shirt in front of all the other kids and... you get a lot of fun poked at you. It was very hard as a child. I think we should give them that dignity... They might be children but they're also human. (P26)

\section{DISCUSSION}

As is the case for any programme that delivers vaccines to schoolchildren, parents are key stakeholders and their perspectives and recommendations are valuable for a programme's success. In our study, parents noted several benefits of SBII, including the convenience of having their child vaccinated without disruption to the family routine and the potential for higher vaccine uptake resulting in reductions in disease transmission (thus ultimately also in reductions in burden for acute care). However, our findings suggest that for such a programme to succeed, parents must understand how it will be managed and coordinated, and perceive that they have sufficient information to make an informed and voluntary decision about their child's participation. Consistent messaging on these issues is essential.

On the basis of their concerns around school resources, it appears that some parents were not aware that Ontario's current school-based vaccination programme is actually offered and delivered by public health nurses, albeit in school. In Ontario, the schoolbased immunisations are given in grades 7 (Meningococcal conjugate (Men-C-ACYW) vaccine, hepatitis $\mathrm{B}$ vaccine) and 8 (HPV vaccine, girls only). ${ }^{26}$ We note that many participants had children in kindergarten to grade 6 (K-6) and suspect that they had not yet had experience with these programmes where they might have learned this. We propose that messaging that vaccination in the school setting is a public health programme must be part of any future SBII programme, and that it might be appropriate regardless, to deliver this message to parents of children in K-6. Parental concerns about impacts of a future SBII programme might also have arisen because of a lack of experience with the current school-based vaccination programme. However, since the schools are themselves key stakeholders in an SBII programme, future research needs to address the 
concerns of schools, and messaging related to any future SBII programme must make it clear that this consultation has occurred.

Our results are similar to those found elsewhere. In the USA, FGs and surveys of parents of children from all grade levels of school (elementary, middle school and high school) have found that convenience is perceived to be an advantage of delivering influenza vaccine at schools; however, concerns about vaccine effectiveness, vaccine safety, trust issues and the need for better information and effective communication have been common threads in studies of delivering influenza vaccine through schools. ${ }^{27-29}$ Similarly, programme coordination, implementation and management issues were issues of importance to parents, including such issues as children being immunised in the absence of a parent, worries about the impacts of peer pressure on their children and a need for reassurance that immunisation would be performed by qualified, credentialed professionals. ${ }^{27}$ These concerns can be managed based on the American experience with school delivery of influenza vaccines ${ }^{30}$ and Australian experience with school delivery of HPV vaccines. ${ }^{31}{ }^{32}$ In Ontario where there is universal, publicly funded influenza immunisation, although vaccine may be provided in pharmacies and mass public health immunisation clinics, the vaccine is most frequently provided in physician offices. ${ }^{13} 14$ Other publicly funded vaccines recommended for school-age children are provided in schools by public health nurses as mentioned previously. As suggested elsewhere, ${ }^{33}$ involving family physicians and other healthcare providers in presenting unified support for school delivery of influenza vaccine may help to alleviate parents' concerns with delivery of influenza vaccine in an environment outside of their medical home.

Our study had some limitations. Participants of the internet forums often provided very brief responses, with limited discussion. Future FGs using this type of format should schedule a short time period of $30 \mathrm{~min}$ to an hour for all participants to join the online discussion simultaneously to encourage stronger engagement and richness of response. As with all qualitative research, it is unknown whether the opinions expressed by our participants are representative of Ontario parents. Study participants were not statistically representative of the Ontario population: a higher proportion had a university degree than the population generally $(67 \%$ vs $25.9 \%) .{ }^{34}$ We sought information solely from parents; future studies should include other important stakeholders such as school board officials and health unit management and staff.

Nonetheless, the findings of this study will inform public health officials and programme managers about the potential acceptability of SBII programmes from the parental perspective. These recommendations may also be useful for evaluators of any of the currently existing immunisation programmes delivered in schools in Ontario. Future research should focus on confirming our results through quantitative analysis, and also seek input from other stakeholders, such as public health and educators.

Collaborators PCIRN Program Delivery and Evaluation members are: Julie Bettinger, Stephanie Brien, David Buckeridge, Jemila Hamid, Natasha Crowcroft, Shelley Deeks, Michael Finkelstein, Maryse Guay, Jeff Kwong, Allison McGeer, Jennifer Pereira, Susan Quach, Sherman Quan, Margaret L Russell.

Contributors MLR and JCK conceptualised the study, monitored data collection and drafted and revised the paper. DM developed the analysis plan, participated in the analysis, and drafted and revised the paper. DM is the guarantor. LC, JAP and SQ conducted the data collection and analysis, and drafted and revised the paper. AEW participated in the analysis and revised the paper. HR participated in the data collection. MIS contributed to the study design, specifically data acquisition. All the authors reviewed and approved the manuscript as submitted. All the authors had full access to all of the data in the study and can take responsibility for the integrity of the data and the accuracy of the data analysis.

Funding This work was funded by the Canadian Institutes of Health Research (grant number PIR 124309).

\section{Competing interests None.}

Ethics approval The study was ethically approved by the Research Ethics Boards of the University of Toronto (University of Toronto Health Sciences Research Ethics Board, protocol \# 28086) and Bruyère Continuing Care Research Ethics Board (protocol \# M16 - 12 - 035)

Provenance and peer review Not commissioned; externally peer reviewed.

Data sharing statement No additional data are available.

Open Access This is an Open Access article distributed in accordance with the Creative Commons Attribution Non Commercial (CC BY-NC 3.0) license, which permits others to distribute, remix, adapt, build upon this work noncommercially, and license their derivative works on different terms, provided the original work is properly cited and the use is non-commercial. See: http:// creativecommons.org/licenses/by-nc/3.0/

\section{REFERENCES}

1. Brownstein JS, Kleinman KP, Mandl KD. Identifying pediatric age groups for influenza vaccination using a real-time regional surveillance system. Am J Epidemiol 2005;162:686-93.

2. Schanzer D, Vachon J, Pelletier L. Age-specific differences in influenza A epidemic curves: do children drive the spread of influenza epidemics? Am J Epidemiol 2011;174:109-17.

3. Fox JP, Cooney MK, Hall CE, et al. Influenzavirus infections in Seattle families, 1975-1979. II. Pattern of infection in invaded households and relation of age and prior antibody to occurrence of infection and related illness. Am J Epidemiol 1982;116:228-42.

4. Glezen WP, Couch RB, MacLean RA, et al. Interpandemic influenza in the Houston Area, 1974-76. N Engl J Med 1978;298:587-92.

5. Monto AS, Koopman JS, Longini IM. Tecumseh study of illness. XIII. Influenza infection and disease, 1976-1981. Am J Epidemiol 1985;121:811-22

6. Esposito S, Marchisio P, Cavagna R, et al. Effectiveness of influenza vaccination of children with recurrent respiratory tract infections in reducing respiratory-related morbidity within the households. Vaccine 2003;21:3162-8.

7. Piedra PA, Gaglani MJ, Kozinetz CA, et al. Herd immunity in adults against influenza-related illnesses with use of the trivalent-live attenuated influenza vaccine (CAIV-T) in children. Vaccine 2005;23:1540-8.

8. Weycker D, Edelsberg J, Elizabeth Halloran M, et al. Population-wide benefits of routine vaccination of children against influenza. Vaccine 2005;23:1284-93.

9. Glezen WP. Herd protection against influenza. J Clin Virol 2006;37:237-43.

10. Basta NE, Chao DL, Halloran ME, et al. Strategies for pandemic and seasonal influenza vaccination of schoolchildren in the United States. Am J Epidemiol 2009;170:679-86.

11. Loeb M, Russell ML, Moss L, et al. Effect of influenza vaccination of children on infection rates in Hutterite communities: a randomized trial. JAMA 2010;303:943-50. 
12. National Advisory Committee on Immunization. Statement on seasonal influenza vaccine for 2013-2014. Can Commun Dis Rep 2013;39(ACS4):1-37.

13. Moran K, Maaten S, Guttmann A, et al. Influenza vaccination rates in Ontario children: implications for universal childhood vaccination policy. Vaccine 2009;27:2350-5.

14. Kwong JC, Ge H, Rosella LC, et al. School-based influenza vaccine delivery, vaccination rates, and healthcare use in the context of a universal influenza immunization program: an ecological study. Vaccine 2010;28:2722-9.

15. Falagas ME, Zarkadoulia E. Factors associated with suboptimal compliance to vaccinations in children in developed countries: a systematic review. Curr Med Res Opin 2008;24:1719-41.

16. Public Health Agency of Canada. Publicly funded immunization programs in Canada-routine schedule for infants and children including special programs and catch-up programs (as of March 2013). Public Health Agency of Canada. 2013 (cited 27 Sept 2013). http://www.phac-aspc.gc.ca/im/ptimprog-progimpt/table-1-eng.php

17. Guide to Community Preventive Services. Universally recommended vaccinations: vaccination programs in schools \& organized child care centers (abbreviated). 2009.

18. Musto R, Siever J, Johnston J, et al. Social equity in human papillomavirus vaccination: a natural experiment in Calgary Canada. BMC Public Health 2013;13:640.

19. Sandelowski M. Whatever happened to qualitative description? Res Nurs Health 2000;23:334-40.

20. Krueger RA, Casey MA. Focus groups: a practical guide for applied research. 4th edn. Thousand Oaks, CA: Sage Publications Inc., 2009.

21. Nicholas DB, Lach L, King G, et al. Contrasting internet and face-to-face focus groups for children with chronic health conditions: outcomes and participant experiences. Int J Qual Methods 2010;9:105-21

22. Quach S, Pereira AJ, Russell ML, et al. The good, bad, and ugly of online recruitment of parents for health-related focus groups: lessons learned. J Med Internet Res 2013;15:e250.
23. du Plessis V, Beshiri R, Bollman RD. Definitions of rural. Rural Small-Town Can Analy Bulletin 2001;3:1-17.

24. Sandelowski M. What's in a name? Qualitative description revisited. Res Nurs Health 2010;33:77-84.

25. Braun V, Clarke V. Using thematic analysis in psychology. Qual Res Psychol 2006;3:77-101.

26. Ontario Ministry of Health and Long-Term Care. Immunization: school age children. Ontario Ministry of Health and Long-Term Care, 2014. http://www.health.gov.on.ca/en/public/programs/immunization/ school_age.aspx

27. Middleman AB, Short MB, Doak JS. School-located influenza immunization programs: factors important to parents and students. Vaccine 2012;30:4993-9.

28. Bhat-Schelbert K, Lin CJ, Matambanadzo A, et al. Barriers to and facilitators of child influenza vaccine: perspectives from parents, teens, marketing and healthcare professionals. Vaccine 2012;30:2448-52.

29. Herbert NL, Gargano LM, Painter JE, et al. Understanding reasons for participating in a school-based influenza vaccination program and decision-making dynamics among adolescents and parents. Health Educ Res 2013;28:663-72.

30. Rand CM, Humiston SG, Schaffer SJ, et al. Parent and adolescent perspectives about adolescent vaccine delivery: practical considerations for vaccine communication. Vaccine 2011;29:7651-8.

31. Robbins SCC, Bernard D, McCaffery K, et al. 'It's a logistical nightmare!' Recommendations for optimising human papillomavirus school-based vaccination experience. Sex Health 2010;7:271-8.

32. Williams V, Rousculp MD, Price M, et al. Elementary school-located influenza vaccine programs: key stakeholder experiences from initiation to continuation. J Sch Nurs 2012;28:256-67.

33. Clevenger LM, Pyrzanowski J, Curtis CR, et al. Parents' acceptance of adolescent immunizations outside of the traditional medical home. $J$ Adolesc Health 2011;49:133-40.

34. Statistics Canada. Education in Canada: Attainment, field of study and location of study: National Household Survey 2011. Catalogue no. 99-012-X2011001, 1-19. 6-18-2013. 